\title{
Refractory pouchitis: does it reflect underlying Crohn's disease?
}

K Subramani, N Harpaz, J Bilotta, C Bodian, P H Rubin, H D Janowitz, I M Gelernt, D B Sachar

\begin{abstract}
Typical 'pouchitis' is a well recognised complication of ileal pouches in ulcerative colitis. Infrequently, a refractory pouchitis (RP) presents with certain clinical, endoscopic, and pathological features resembling Crohn's disease and is often ascribed to misdiagnosis of the initial colitis. To test that hypothesis and to identify risk factors for $R P$, this study reviewed cases of presumed ulcerative colitis with ileal pouches constructed at The Mount Sinai Hospital between 1973 and 1986. Twenty four cases with RP (16 Kock pouches and eight pelvic pouches) and 21 controls were compared for eight clinical variables. The original colectomy slides from $15 \mathrm{RP}$ and 18 control cases were reviewed blindly, classified into five histological categories (corresponding to definite ulcerative colitis, definite Crohn's disease, and three indeterminate groups), and scored for 23 histological features. There were no significant clinical differences between RP and control cases except for more frequent extraintestinal manifestations (38\% v 5\%) and male preponderance $(79 \% v 43 \%)$ in RP. There were also no significant differences between the distributions of RP cases and controls among the five histological categories or in the 23 histological features studied. Refractory pouchitis therefore does not seem to reflect underlying Crohn's disease, but may be linked to immunological mechanisms that are manifested clinically as extraintestinal complications.
\end{abstract}

(Gut 1993; 34: 1539-1542)

Departments of Medicine (Division of

Gastroenterology),

K Subramani

J Bilotta

P H Rubin

H D Janowitz

D B Sachar

Pathology,

N Harpaz

Biomathematical Sciences, C Bodian

and Surgery, The Mount Sinai Hospital and The Mount Sinai School of Medicine of the City Medicine of the City USA

I M Gelernt

Correspondence to:

Dr $N$ Harpaz, Department of Pathology, The Mount Sinai Medical Center, One Gustave L Levy Place, New York NY 10029, USA.

Accepted for publication 8 April 1993
Florid active mucosal inflammation with disturbed bowel function, often called 'pouchitis', is a comparatively common complication of ileal reservoirs created after colectomy, usually for ulcerative colitis, occurring in roughly $20 \%$ of cases (range 7-42\%). ${ }^{1-4}$

Pouchitis usually responds well to treatment with antibiotics, but in a small subset of cases the inflammation is clinically severe, endoscopically atypical, and relatively refractory to conventional treatment. These cases seem to represent a distinct inflammatory condition, which we have termed 'refractory pouchitis' (RP). Because the endoscopical features of RP are not dissimilar to those of Crohn's ileitis, RP has often been attributed to underlying Crohn's disease, presumably 'misdiagnosed' as ulcerative colitis pre and perioperatively. To test the validity of this notion and to identify potential risk factors for RP, we reviewed our cases of RP at The Mount Sinai Hospital and compared the pathological features of their colectomy specimens as well as
TABLE I Endoscopic lesions in refractory pouchitis

\begin{tabular}{lc}
\hline Lesions & No of patients \\
\hline Aphthous ulcers & 6 \\
Serpiginous ulcers & 8 \\
Ileitis proximal to reservoir & 14 \\
Cobblestone mucosa & 4 \\
\hline
\end{tabular}

their clinical features to those of a control group without RP.

\section{Patients}

All cases were selected from ileal pouches constructed between 1973 and 1986 at The Mount Sinai Hospital.

Refractory pouchitis - We selected 24 cases that were well known to their gastroenterologists and that fit the clinical, endoscopical, and pathological criteria for RP as adopted at an International Workshop on Pouchitis in London in January 1989,5 including clinical symptoms (bloody diarrhoea, malaise, or weight loss, or all three); resistance to treatment with antibiotics and steroids; and endoscopical features (serpiginous ulcerations, cobblestone mucosa, or ileitis proximal to the reservoir, or all three). ${ }^{6-8}$ Table I shows the frequency of each of the defining endoscopic lesions; in some cases, of course, more than one feature was present. Biopsies of the pouches of all these patients were reported as showing active chronic inflammation. The mean duration between pouch construction and onset of pouchitis was 22.3 months (range 2-72 months). Four of the $24 \mathrm{RP}$ patients ultimately required pouch removal and conversion to a standard Brooke ileostomy.

Controls comprised 21 patients with ileal pouches constructed during the same period who had been followed up for a mean duration of 43 months (range 15-119 months) and who had had endoscopies that showed no evidence of active inflammation. Table II shows the distribution of Kock pouches (continent ileostomies) and pelvic pouches between RP cases and controls.

The medical records of all cases were reviewed for the following eight clinical features: sex, age at onset of colitis, age at colectomy, indications for colectomy, age at time of pouch construction, extraintestinal manifestations before colectomy,

TABLE II Distribution of pouches in the group

\begin{tabular}{lll}
\hline Type of pouch & $R P(n=24)$ & Controls $(n=21)$ \\
\hline 1 Kock & 16 & 16 \\
2 Ileoanal or pelvic & 8 & 5 \\
\hline
\end{tabular}

$\mathrm{RP}=$ refractory pouchitis 
TABLE III Histological classification of colectomy specimens

\begin{tabular}{ll}
\hline Category & Criteria \\
\hline A & $\begin{array}{l}\text { Definite UC; diffuse, continuous proctocolitis limited to mucosa and superficial } \\
\text { submucosa. } \\
\text { Highly suggestive of UC, but focally evincing one of several histological features more } \\
\text { commonly associated with CD than UC, for example, cleft like mucosal ulceration, } \\
\text { neuronal hyperplasia, intramural lymphoid aggregates beneath intact mucosa, } \\
\text { submucosal lymphangiectasia; also fulminant colitis, even if lacking any of these } \\
\text { features. }\end{array}$ \\
C & $\begin{array}{l}\text { Indeterminate colitis, with more than one, or increased prominence, of the histological } \\
\text { features indicated for category B; also fulminant colitis with any one of these features. } \\
\text { Indeterminate colitis, suggestive of CD, with one or more histological features considered } \\
\text { characteristic of CD, for example, skip segments, focality of inflammation, fissuring } \\
\text { ulcerations, focal chronic ileitis with pseudopyloric metaplasia; no diagnostic } \\
\text { granulomata. }\end{array}$ \\
Definite CD, with typical granulomata in an appropriate histological setting.
\end{tabular}

$\mathrm{UC}=$ ulcerative colitis, $\mathrm{CD}=$ Crohn's disease.

use of steroids before colectomy, and immediate postcolectomy complications.

\section{Methods}

Microscopic slides of 33 resection specimens were available for review ( 31 from The Mount Sinai Hospital and two from other hospitals), comprising 15 patients with RP and 18 controls. The specimens consisted of 21 total colectomies (several performed in two stages), 11 subtotal colectomies, and one second stage proctosigmoidectomy for which the corresponding colectomy specimen was not available. The original pathological diagnoses were either ulcerative colitis or indeterminate. The original macroscopic descriptions were reviewed to ensure that the available slides represented an adequate sampling of significant pathology. All slides were then reviewed by one pathologist $(\mathrm{NH})$, who was aware that the cases comprised both RP and control groups but who had not seen the cases previously and had no knowledge of individual clinical histories or outcomes. An average of 15 sections (range 7-32) were available for both total and subtotal colectomies and six sections for the single proctosigmoidectomy, not counting sections of lymph nodes and stomas. Gross photographs of specimens were not examined, as they were not available for all cases.

Based on the microscopic review, each case

TABLE IV Individual histological features

Left to right gradient of chronic colitis $(+/-)$

Skipped segments $(+/-)$

Chronic ileitis $(+/-)$

Anal inflammation $(+/-)$

Microscopic focal inflammation $(+/-)$

Aphthous ulcers (+/-)

Sarcoid like granulomata $(+/-)$

Maximum depth of chronic inflammatory infiltrates beneath intact mucosa

Fissures: frequency ( 0 to $3+)$, depth

Ulcers: frequency $(0$ to $3+)$, depth*

Lymphoid aggregates: frequency $(0$ to $3+)$, depth ${ }^{\star}$

Activity of mucosal inflammation ( 0 to $3+$ )

Activity of mucosal inflammation ( 0 to $3+)$

Paneth cell metaplasia (0 to $3+\cdot)$

Paneth cell metaplasia ( 0 to $3+$ )
Neuronal hyperplasia ( 0 to $3+$ )

Neuronal hyperplasia ( 0 to

Mucus secretion (0 to
Hyperemia (0 to 3+)

Hyperemia (0 to 3+)
Submucosal lymphangiectasia

Submucosal lymphangiectasia (0 to $3+$ )

Submucosal fibrosis ( 0 to 3
Submucosal fat ( 0 to $3+$ )

Submucosal fat (0 to $3+)$

Submucosal vascularity (0 to
Follicular proctitis $(0$ to $3+)$

Follicular proctitis ( 0 to $3+$ )

Rectal crypt atrophy (0 to $3+$ )

^ Maximum depths of fissures, ulcers, chronic inflammatory infiltrates, and lymphoid aggregates graded as follows: superficial, infiltrates, and lymphoid aggregates graded as follows: superficial, mid, or
serosa.
TABLE V Precolectomy clinical features

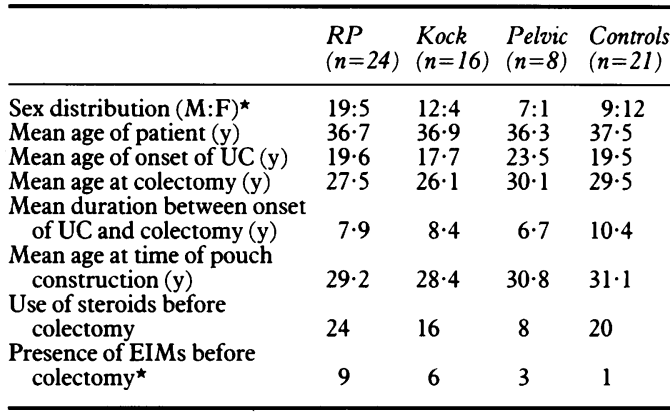

^Statistically significant differences between RP and controls. $\mathrm{RP}=$ refractory pouchitis, $\mathrm{UC}=$ ulcerative colitis,

EIMs = extraintestinal manifestations.

was assigned to one of five histological categories: cases representing definite ulcerative colitis were assigned to category $\mathrm{A}$, cases representing definite Crohn's disease to category $\mathbf{E}$, and cases containing overlapping features to indefinite categories $\mathrm{B}, \mathrm{C}$, or $\mathrm{D}$, depending on the prominence and diagnostic significance of these features (Table III). Each case was also evaluated and graded for 23 individual histological features (Table IV), mostly those considered useful in the differential diagnosis of ulcerative colitis and Crohn's disease, but including others that were added in the search for histological features that might distinguish RP from controls.

Differences in the sex distribution and in the frequency of precolectomy extraintestinal manifestations were analysed by the $\chi^{2}$ test and the remaining clinical variables by the Student $t$ test. An association of each of the histological features with the presence or absence of pouchitis was sought by the $\chi^{2}$ test.

\section{Results}

Table $\mathrm{V}$ shows the comparison of clinical features between RP cases and controls. There was no statistically significant difference between the two groups except for sex distribution and frequency of precolectomy extraintestinal manifestations. Refractory pouchitis patients showed a male preponderance of $79 \% v$ $43 \%$ in the control cases $(p<0.03)$. They also had more prevalent precolectomy extraintestinal manifestations of $38 \%(9 / 24) v 5 \%(1 / 21)$ in the controls $(p<0.025)$. These clinical profiles of RP cases did not differ significantly between Kock and pelvic pouches (Table V). Table VI shows the specific extraintestinal manifestations in the $\mathrm{RP}$ and control groups. In three of the RP cases, but in none of the controls, extraintestinal manifestations had provided the principal indication

TABLE VI Distribution of extraintestinal manifestations (EIMs)

\begin{tabular}{lll}
\hline EIMs & $\begin{array}{l}R P \\
(n=24)\end{array}$ & $\begin{array}{l}\text { Controls } \\
(n=21)\end{array}$ \\
\hline $\begin{array}{l}\text { Erythema nodosum alone } \\
\text { Erythema nodosum + arthritis }\end{array}$ & 5 & 1 \\
Pyoderma gangrenosum alone & 1 & 0 \\
Pyoderma gangrenosum + arthritis & 1 & 0 \\
Arthritis alone & 1 & 0 \\
Total & 9 & 0 \\
\hline
\end{tabular}


TABLE VII Indications for colectomy and perioperative features

\begin{tabular}{lcc}
\hline & $\begin{array}{l}R P \text { cases } \\
(n=21)\end{array}$ & $\begin{array}{l}\text { Controls } \\
(n=21)\end{array}$ \\
\hline Intractability & 13 & 13 \\
Bleeding & 3 & 4 \\
EIMs & 3 & 0 \\
Perforation & 1 & 1 \\
Dysplasia & 1 & 1 \\
Toxic megacolon & 2 & 2 \\
Growth failure & 1 & 0 \\
Emergency colectomy & 5 & 4 \\
Elective colectomy & 19 & 17 \\
Immediate postoperative complications & 1 & 2 \\
\hline
\end{tabular}

Abbreviations the same as in Table V.

TABLE VIII Histological classification of resected colons

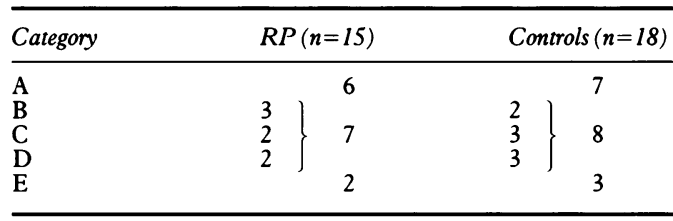

for colectomy (Table VII); otherwise, the surgical indications were nearly identical between the two groups. It has been suggested that emergency colectomy and postoperative sepsis may predispose to the development of pouchitis. ${ }^{14}$ Our review of clinical features, however, found no increased incidence of pouchitis in cases that had had emergency colectomy or postoperative sepsis (Table VII).

As shown in Table VIII, the 13 cases that were judged histologically to be definite ulcerative colitis (category A) were distributed almost evenly between the RP and control groups. By the same token, five cases representing Crohn's disease (category E) by virtue of containing sarcoid like granulomata (evidently overlooked by the original pathologists), as well as 15 cases with varying degrees of overlapping histology (categories B, C, and D), were also distributed almost evenly between the two groups. Finally, there were no statistically significant associations of RP $v$ control classification with any of the 23 individual histological features listed in Table IV, including the presence of chronic ileitis.

\section{Discussion}

Typical pouchitis has been reported in about $20 \%$ of ileal reservoirs, although incidences in different series range from $7-42 \%$, with equal frequency in both pelvic and Kock pouches. ${ }^{1-39-17}$ By contrast, the syndrome that we have termed refractory pouchitis (RP) is comparatively rare. It may correspond to what the Lahey Clinic group has called 'chronic' pouchitis. ${ }^{18}$ Our cases of RP represent only about 3\% of the ileal pouches constructed at The Mount Sinai Hospital during the 13 year period studied.

The mean interval from reservoir surgery to onset of pouchitis in our series was 22 months (range 2-72 months). This figure conforms closely to the experience of others. Zuccaro et al ${ }^{19}$ reported a mean interval of 25 months (range 3-54 months) and Lohmuller et $a l^{20}$ reported a mean interval of 17 months (range 2 days93 months). There may in fact be some differences in these time intervals and in other patho- genetic factors between Kock pouches and pelvic pouches, but in view of the general clinical similarities between the RP syndromes in these two forms of pouch (Table V), we have felt justified in combining them for the purposes of our analysis.

Because the endoscopical findings in RP often include serpiginous ulcerations, fissures, and ileitis proximal to the pouch, the syndrome has often been attributed to underlying Crohn's disease, the diagnosis of which had presumably been 'missed' both clinically and pathologically up to and including the time of colectomy. There has been no systematic study, however, to discover if this assumption is correct. We therefore sought clinical and pathological features that might test this concept and help us identify risk factors for the development of RP.

The only distinguishing clinical features we could identify in the RP group were male preponderance and an increased frequency of extraintestinal manifestations. We are not aware that a male preponderance has been previously seen in association with any form of pouchitis. Lohmuller et $a l^{20}$ reported that among 671 patients with chronic ulcerative colitis, if preoperative extraintestinal manifestations had been present, pouchitis occurred in $39 \%$ of cases, but in only $26 \%$ if no extraintestinal manifestations had been present. They also showed by lifetable analysis that the risk of pouchitis at 5 years was $44 \%$ if preoperative extraintestinal manifestations had been present $v 33 \%$ if they had been absent. Similarly Becker et $a l^{21}$ reported that if their ulcerative colitis patients had preoperative extraintestinal manifestations, $39 \%$ developed pouchitis $v$ only $19 \%$ among those patients who had not had preoperative extraintestinal manifestations. Indeed, severe systemic manifestations have been reported in the course of pouch ileitis itself. ${ }^{22}$

Blind pathological review of the colectomy specimens showed no correlation between histological category and the presence or absence of RP. For example, colectomy specimens were classified as definite ulcerative colitis (Group A) as frequently in RP as in controls ( $40 \%$ and $39 \%$, respectively). This lack of significant difference between the proportions of RP cases and controls held true for the other histological categories as well, including even patients with definite Crohn's disease (Group E) (RP 13\%, control $17 \%)$. Our findings are supported by the Mayo Clinic report of no increased incidence of pouchitis in cases of histologically indeterminate colitis compared with cases of more classic ulcerative colitis. ${ }^{23}$

Our review also attempted to discern any correlation between RP and individual histological features, primarily those considered to be indicators of classic Crohn's disease, but we found no such associations. For example, the same proportions of RP and control patients had histological evidence of ileitis on review of their surgical specimens ( $20 \%$ and $17 \%$, respectively). This particular finding supports the finding, based on radiological studies, that the presence of backwash ileitis did not predispose to an increased incidence of pouchitis. ${ }^{24}$

It should be emphasised that even the five 
cases classified pathologically as Group E were not histologically compelling examples of classic Crohn's disease apart from the presence of typical granulomata. Granulomata themselves were comparatively infrequent, and other histological features characteristic of Crohn's disease were less conspicuous than usual. Therefore, we are not implying that patients with classic Crohn's disease are necessarily good candidates for reservoir surgery, nor does the recent experience of The Cleveland Clinic support such a view. ${ }^{25} \mathrm{We}$ are suggesting, however, that the postoperative development of RP is not prima facie evidence for a 'missed' diagnosis of Crohn's disease before and including the time of colectomy.

The cause of RP may be linked to the still unelucidated immunological mechanisms in inflammatory bowel disease that are clinically manifested as extraintestinal complications. Perhaps an immunologically vulnerable subset of inflammatory bowel disease patients, Crohn's disease and ulcerative colitis alike, are prone to develop refractory pouchitis under the influence of certain mechanical, vascular, bacteriological or biochemical factors, or all four that may arise in an ileal reservoir. ${ }^{26-29}$ This concept may explain why the inflammatory changes manifested in the clinical syndrome of 'pouchitis' are seen almost exclusively in patients who have had colectomy for inflammatory bowel disease rather than for familial polyposis. ${ }^{19}$

Whatever the pathophysiological basis of RP may be, however, it is worthy of serious study as a 'human experimental model' of inflammatory bowel disease, ${ }^{30}$ rather than cavalier dismissal as simply a 'misdiagnosis' of Crohn's disease.

This work was accepted for poster presentation at the Digestive Disease Week held in May 1990 at San Antonio, TX, and published in abstract form (Gastroenterology 1990; 98: A205)

1 Dozois RR, Goldberg SM, Rothenberger DA, Utsunomiya J, Nicholls RJ, Cohen Z, et al. Restorative proctocolectomy Nicholls RJ, Cohen Z, et al. Restorative proctocolecto
with ileal reservoir. Int $\mathcal{F}$ Colorectal Dis 1986; 1: 2-19.

2 Pemberton JH, Kelly KA, Beart RW Jr, Dozois RR, Wolff $\mathrm{BG}$, Ilstrup DM. Ileal pouch-anal anastomosis for chronic ulcerative colitis: long term results. Ann Surg 1987; 206: 504-13.

3 Tytgat GN, Van DeVenter SJ. Pouchitis. Int $\mathcal{F}$ Colorectal Dis 1988; 3: 226-8.

4 Madden MV, Farthing MJ, Nicholls RJ. Inflammation in ileal reservoirs: 'pouchitis'. Gut 1990; 31: 247-9.

5 Nicholls RJ. Work Shop: pouchitis - clinical diagnosis. Int $\mathcal{F}$ Colorectal Dis 1989; 4: 213-6.

6 Shepherd NA, Jass JR, Duval I, Moskowitz RL, Nicholls RJ, Morson BC. Restorative proctocolectomy with ileal Morson BC. Restorative proctocolectomy with ileal biopsy specimens. f Clin Pathol 1987; 40: 601-7.
7 Nilsson LO, Kock NG, Lindgren I, Myrvold HE, Philipson BM, Ahren C. Morphological and histochemical changes in the mucosa of the continent ileostomy reservoir 6-10 years after its construction. Scand $\mathcal{F}$ Gastroenterol 1980; 15 $737-47$

8 Waye JD. Endoscopy in follow up of continent ileostomy. In: Bayless T, ed. Current management of inflammatory bowel disease. Toronto, Philadelphia: BC Decker, 1989. $123-6$.

9 Becker JM, Raymond JL. Ileal pouch-anal anastomosis: a single surgeon's experience with 100 consecutive cases. Ann Surg 1986; 204: 375-83.

10 Fleshman JW, Cohen Z, McLeod RS, Stern H, Blair J. The ileal reservoir and ileoanal anastomosis procedure: factors affecting technical and functional outcome. Dis Colon Rectum 1988; 31: 10-6.

11 Kock NG, Myrvold HE, Nilsson LO, Philipson BM Continent ileostomy: an account of 314 patients. Acta Chir Scand 1981; 147: 67-72.

12 Hulten L, Svaninger G. Facts about Kock continent ileostomy. Dis Colon Rectum 1984; 27 : 553-7.

13 Goldman SL, Rombeau JL. The continent ileostomy: a collective review. Dis Colon Rectum 1978; 21: 594-9.

14 Jarvinen HJ, Makitie A, Sivula A. Long-term results of continent ileostomy. Int $\mathcal{F}$ Colorectal Dis 1986; 1: 40-3.

15 Ojerskog B, Kock NG, Nilsson LO, Philipson BM, Ahren C. Long-term follow-up of patients with continent ileostomies. Dis Colon Rectum 1990; 33: 184-9.

16 Everett WG. Experience of restorative proctocolectomy with ileal reservoir. Br $\mathcal{F}$ Surg 1989; 76: 77-81.

17 Pescatori M, Mattana C, Castagneto $M$. Clinical and functional results after restorative proctocolectomy. BrF Surg 1988; 75: $321-4$

18 Rauh SM, Schoetz DJ Jr, Roberts PL, Murray JJ, Coller JA, Veidenheimer MC. Pouchitis - is it a wastebasket diagnosis? Dis Colon Rectum 1991; 34: 685-9.

19 Zuccaro G Jr, Fazio VW, Church JM, Lavery IC, Ruderman WB, Farmer RG. Pouch ileitis. Dig Dis Sci 1989; 34: 1505-10.

20 Lohmuller JL, Pemberton JH, Dozois RR, Ilstrup DM, van Heerdan J. Pouchitis and extraintestinal manifestations of inflammatory bowel disease after ileal pouch-anal anastomosis. Ann Surg 1990; 211: 622-7.

21 Becker JM, Dunnegan DD. Ileal pouch and dysfunction following ileal pouch-anal anastomosis. In: MacDermott RP, ed. Inflammatory bowel disease: current therapy and future RP, ed. Inflammatory bowel disease: current therapy and future approach. Amst

22 Klein K, Stenzel P, Katon RM. Pouch ileitis: report of a case with severe systemic manifestations. $\mathcal{f}$ Clin Gastroenterol 1983; 5: 149-53.

23 Pezim ME, Pemberton JH, Beart RW Jr, Wolff BG, Dozois RR, Nivatvongs $S$, et al. Outcome of 'indeterminant' colitis following ileal pouch-anal anastomosis. Dis Colon Rectum 1989; 32: 653-8.

24 Gustavsson S, Weiland LH, Kelly KA. Relationship of backwash ileitis to ileal pouchitis after ileal pouch-anal anastomosis. Dis Colon Rectum 1987; 30: 25-8.

25 Hyman NH, Fazio VW, Tuckson WB, Lavery IC. Consequences of ileal pouch-anal anastomosis for Crohn's colitis. quences of ileal pouch-anal anastom

26 Nasmyth DG, Johnston D, Godwin PG, Dixon MF, Smith A Williams NS. Factors influencing bowel function after ileal pouch-anal anastomosis. Br f Surg 1986; 73: 469-73.

27 Nicholls RJ, Belliveau P, Neill M, Wilks M, Takagchali S Restorative proctocolectomy with ileal reservoir: a pathophysiological assessment. Gut 1981; 22: 462-8.

28 Brandberg A, Kock NG, Philipson B. Bacterial flora in intraabdominal ileostomy reservoir. Gastroenterology 1972 63: 413-6

29 Luukkonen P, Valtonen V, Sivonen A, Sipponen P, Jarvinen $H$. Fecal bacteriology and reservoir ileitis in patients operated on for ulcerative colitis. Dis Colon Rectum 1988; 31 : $864-7$.

30 Sachar DB. 1989 Henry Baker Lecture. Inflammatory bowe disease: back to the future. Am $\mathcal{F}$ Gastroenterol 1990; 85: $373-6$. 